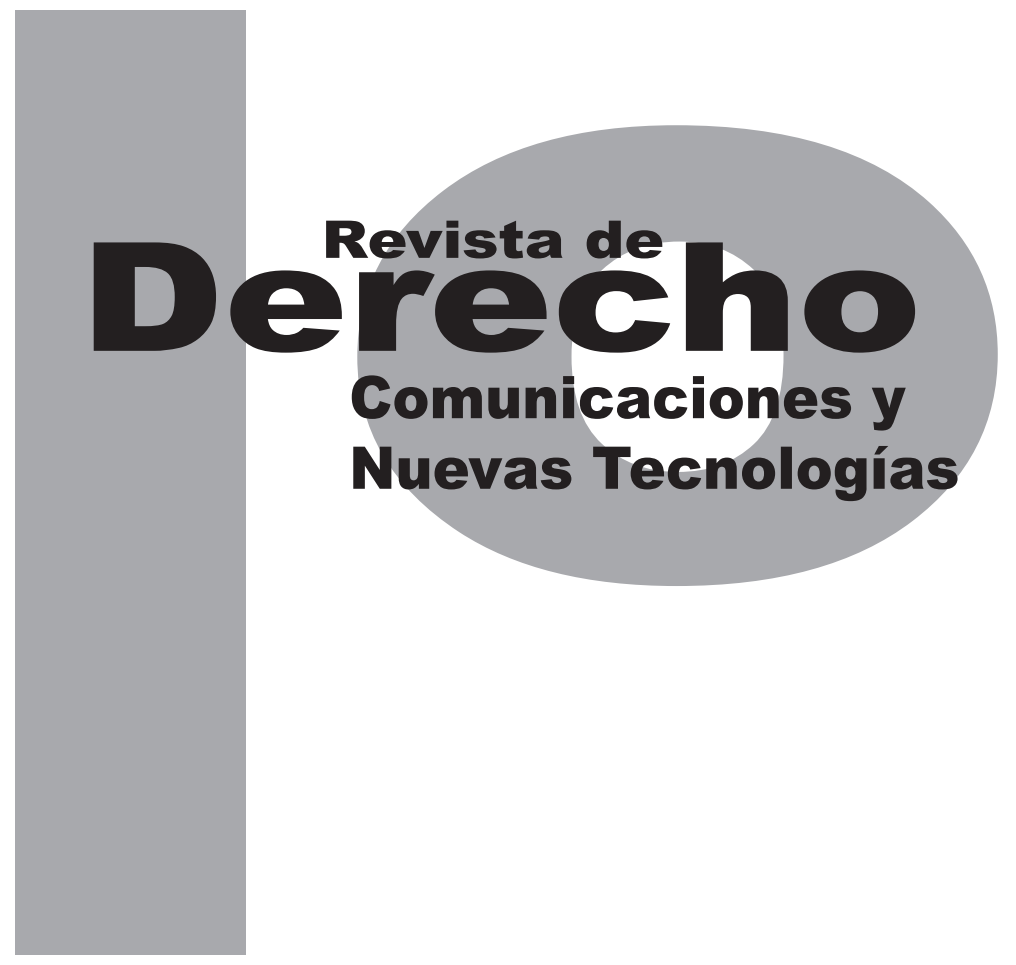

\title{
LA INFLUENCIA DE LAS TIC Y LA EDUCACIÓN CÍVICA EN LOS PROCESOS DELIBERATIVOS DE LAS SOCIEDADES PLURALISTAS
}

\author{
ERIC LEIVA RAMÍREZ
}

Artículo de reflexión

DOI: http://dx.doi.org/10.15425/redecom.14.2015.02

Universidad de los Andes

Facultad de Derecho

Rev. derecho comun. nuevas tecnol.

No. 14, julio - diciembre de 2015. ISSN 1909-7786 


\title{
La influencia de las TIC y la educación cívica en los procesos deliberativos de las sociedades pluralistas
}

\section{Resumen}

Los procesos democráticos actuales se caracterizan, entre otras cosas, por gozar de espacios deliberativos a través de los cuales los diferentes actores sociales exponen sus argumentos en aras de hacer efectivos los presupuestos normativos y éticos consagrados en las cartas de derechos. No obstante, la existencia de procesos educativos tradicionales y carentes de una adecuada comunicación de los presupuestos consagrados en las Constituciones ha conllevado no solo al inapropiado conocimiento de los derechos fundamentales y mecanismos para su protección, sino a la "pobreza" de los argumentos que se exponen para la exigencia de su eficacia tanto normativa como sociológica. Por esta razón, el uso de las tic en los procesos educativos, especialmente aquellos enfocados a la educación cívica, podría llegar a masificar la comunicación de saberes democráticos y generar espacios deliberativos que permitan a los ciudadanos desarrollar competencias apropiadas para los procesos deliberativos. De esta forma, los argumentos expuestos por los actores se fortalecen en argumentos y, por ende, los principios democráticos serían eficaces.

Palabras clave: procesos deliberativos, interculturalidad, pluralismo, educación cívica, тIc, democracia.

\section{The influence of TICS and civic education on the deliberative processes of pluralistic socie- ties}

\begin{abstract}
The current democratic process is characterized, among other things, by the enjoyment of deliberative spaces through which different social actors present their arguments in order to enforce the regulatory and ethical premises enshrined in Colombia's Bill of Rights. However, the existence of traditional educational processes and the lack of adequate communication about the premises enshrined in the Constitutions have led not only to an incorrect understanding of fundamental rights and mechanisms that protect the democratic process, but have also led to weak arguments demanding normative and sociological effectiveness of the democratic process. For this reason, the use of the TICs in education, especially those aimed at civic education, have the possibility of distributing en masse democratic knowledge and generating deliberative democratic spaces that allow citizens to develop appropriate skills for deliberative processes. Thus, the arguments put forth by participants are strengthened and as a result democratic principles would be effective.
\end{abstract}

Keywords: deliberative processes, multiculturalism, pluralism, civic education, TIC, democracy.

\section{A influência das TIC e a educação cívica nos processos deliberativos das sociedades pluralistas}

\section{Resumo}

Os processos democráticos atuais se caracterizam, entre outras coisas, por gozar de espaços deliberativos através dos quais os diferentes atores sociais expõem seus argumentos em aras de tornar efetivos os pressupostos normativos e éticos consagrados nas cartas de direitos. Não obstante, a existência de processos educativos tradicionais e carentes de uma adequada comunicação dos pressupostos consagrados nas Constituições tem implicado não só ao inapropriado conhecimento dos direitos fundamentais e mecanismos para sua proteção, senão à "pobreza" dos argumentos que se expõem para a exigência de sua eficácia tanto normativa quanto sociológica. Por esta razão, o uso das tıc nos processos educativos, especialmente aqueles enfocados na educação cívica, poderia chegar a massificar a comunicação de saberes democráticos e gerar espaços deliberativos que permitam aos cidadãos desenvolver competências apropriadas para os processos deliberativos. Desta forma, os argumentos expostos pelos atores se fortalecem em argumentos e, portanto, os princípios democráticos seriam eficazes.

Palavras-chave: processos deliberativos, interculturalidade, pluralismo, educação cívica, tıc, democracia. 


\title{
La influencia de las TIC y la educación cívica en los procesos deliberativos de las sociedades pluralistas ${ }^{*}$
}

\author{
Eric Leiva Ramírez ${ }^{* *}$
}

\section{SUMARIO}

Introducción - I - EL PLURALISMO EN LAS DEMOCRACIAS DELIBERATIVAS - II- LAS TIC EN LAS SOCIEDADES DEMOCRÁTICAS DELIBERATIVAS - III. LAS TIC Y LA EDUCACIÓN CIVICA - IV. LA EDUCACIÓN CÍVICA INTERCULTURAL PARA SOCIEDADES DEMOCRÁTICAS DELIBERATIVAS - V. CONCLUSIONES - Referencias.

* Cómo citar este artículo: Leiva Ramírez, E. (Diciembre, 2015). La influencia de las tic y la educación cívica en los procesos deliberativos de las sociedades pluralistas. Revista de Derecho, Comunicaciones y Nuevas Tecnologías, 14. Universidad de los Andes (Colombia).

Artículo de reflexión producto del proyecto de investigación Responsabilidad estatal y democracia, realizado como pasante en la Facultad de Ciencias Jurídicas (Grupo de Derecho Administrativo) de la Universidad de Castilla - La Mancha (España).

** Abogado y magíster en Derecho Administrativo. Doctorando en Derecho de la Universidad de los Andes. Docente e investigador universitario. Correos: ea.leiva60@uniandes.edu.co, eric.leiva@ugc.edu.co 
Introducción

Frecuentemente se emplean múltiples expresiones para comunicar lo bondadosa que es la democracia. No obstante, estas se encuentran enmarcadas dentro de un contexto que privilegia los aspectos formales (ejercicio de elecciones libres, libertad para expresarse, rendición de cuentas por parte de las autoridades públicas, etc.) sobre los sustanciales. Prueba de ello son las posturas de algunos iusfilósofos que la conciben como un conjunto de reglas y procedimientos para someter a determinadas decisiones a la mayoría (Sartori, 2009, pág. 330). Sin embargo, esta posición aunque importante y propia de un concepto democrático moderno resulta insuficiente, pues la democracia, más que una forma de gobierno, es una vivencia de la política.

En efecto, los conceptualismos generados por la formalidad jurídica y la economía, que han resultado ajenos a la mayoría de los ciudadanos (Habermas, 1987, pág. 100), han llevado a los teóricos y estudiosos de la ciencia jurídica y la ciencia política a generar conceptualizaciones que permitan materializar y vivenciar los principios y valores consagrados en las cartas de derechos tan en boga a partir de la segunda década del siglo XX. Por ejemplo, el garantismo jurídico propone dos visiones sobre la democracia: una formal -relativa a los procedimientosy otra sustancial -concerniente a los derechos fundamentales que el Estado tiene el deber de garantizar-(Ferrajoli, 2011, pág. 30). Igualmente, el neoconstitucionalismo intenta recuperar el fundamento de las cartas de derechos y su- perar los modelos formalistas sobre los que se legitimaba el Estado de derecho (Prieto, 2002, pág. 38). En este aspecto, la educación cívica juega un papel fundamental en sociedades basadas en principios y valores constitucionales.

La educación cívica es el instrumento a través del cual se puede contar con una ciudadanía activa que dedique parte de su tiempo al bien público. Así, Martí (2006, pág. 298) considera que esta es uno de los pilares de las democracias modernas, fundamentadas en procesos deliberativos de ciudadanos conscientes de sus derechos y garantías constitucionales (pág. 298). Por esta razón, la educación cívica se convierte en un derecho de los ciudadanos y en una obligación del Estado, pues como producto del derecho a la educación (Martí, 2006, pág. 299)1 adquiere la connotación de principio normativo fundamental, que contiene un imperativo positivo que debe ser garantizado por el Estado como derecho social o material que es (Ferrajoli, 1995, pág. 354;² Alexy, 2002, pág. 483). De

"Uno de los pilares centrales de la política de una república deliberativa es por supuesto la educación, y dentro de ésta, la educación cívica. El Estado debe dar todos los pasos necesarios para que el ciudadano saque el máximo partido de sus capacidades intelectuales. Pero el sistema educativo, a su vez, debe transmitir los valores necesarios para una convivencia cívica y democrática que permita el desarrollo de las virtudes públicas de la ciudadanía." (Martí, 2006, pág. 298).

2 "Junto a los tradicionales derechos de libertad, las Constituciones de este siglo han reconocido sin embargo otros derechos vitales o fundamentales: los ya recordados derechos a la subsistencia, a la alimentación, al trabajo, a la salud, a la educación, a la vivienda, a la información y similares. A diferencia de los derechos de libertad, que son derechos (o facultades de comportamientos propios) a los que corresponden prohibiciones (o deberes públicos de no hacer), estos derechos, que podemos llamar "sociales" o también "materiales", son derechos a (o expectativas de comportamientos ajenos) a los que deberían corresponder obligaciones (o deberes públicos de hacer). La noción liberal del "estado de derecho" debe ser, en consecuencia, ampliada para incluir también la figura del estado vinculado por obligaciones además de por prohibiciones. Diremos por consiguiente que cuando un ordenamiento constitucional incorpora 
esta forma, el derecho a la educación adquiere un carácter político, pues a través de él la ciudadanía puede adquirir no solo conocimientos académicos, sino aquellos de contenido democrático, permitiendo estos últimos el ejercicio de las garantías constitucionales que contribuyen a la realización de una constitución viviente (Waluchow, 2009, pág. 376).

El conocimiento de los presupuestos constitucionales puede generar una ciudadanía deliberativa, consciente de su destino político y, por ende, la creación de espacios para ejercer sus derechos. Así, Martí plantea que una sociedad deliberativa real debe "tomar medidas de educación y formación de la ciudadanía en tales virtudes públicas y diseñar mecanismos de participación política que contemplen la posibilidad de que muchos de los participantes pueden ser virtuosos e incentiven la virtud de la ciudadanía" (2006, pág. 297). Por esta razón, la educación cívica permite la comunicación de los presupuestos democráticos de una sociedad políticamente activa. Sobre este aspecto, Habermas (1987, pág. 161) plantea que "todo lo que tiene validez se tiene que justificar públicamente". En efecto, la democracia deliberativa considera la determinación democrática -los espacios privados y pú-

\footnotetext{
sólo prohibiciones, que requieren prestaciones negativas en garantía de los derechos de libertad, se le caracteriza como estado de derecho liberal; cuando por el contrario incorpore también obligaciones, que requieren prestaciones positivas en garantía de derechos sociales, se le caracterizará como estado de derecho social." (Ferrajoli, 1995, pág 861).

Finalmente, Ferrajoli plantea que una derivación del derecho a la vida es el derecho a la supervivencia, que conlleva el ejercicio de varios derechos sociales, como el derecho a la educación. "Vivir no solamente requiere de la prohibición de matar, sino que demanda también de tomar las medidas necesarias mínimas para garantizar la supervivencia a través de la satisfacción de mínimos vitales." (Ferrajoli, 2011, pág. 18).
}

blicos de la vida en común-, como una cuestión que solo es posible solventar a través de la deliberación o la discusión pública abierta a todos los participantes en la sociedad democrática.

La discusión o deliberación pública democrática no puede tener vedado ningún tema ni ninguna forma de entender el bien social. Por ello, la no enseñanza de los principios y valores democráticos es contraria a las obligaciones del Estado social de derecho, pues no posibilita los conocimientos necesarios para que los ciudadanos actúen en la construcción de una democracia deliberativa. Desconocer los presupuestos constitucionales genera debates carentes de argumentos y, por tanto, impropios de una sociedad democrática. Por esta razón, los Estados democráticos deben fortalecer los procesos de educación cívica, pues de esta forma los ciudadanos adquieren los argumentos esenciales para exigir al Estado la protección de los derechos fundamentales consagrados en las disposiciones constitucionales.

Por otro lado, la educación cívica permite formar ciudadanos que contribuyan a la materialización de los principios y valores democráticos a través de vías institucionales como no institucionales. Los presupuestos que se comunican en los procesos de educación constitucional pueden ejercerse i) en espacios de deliberación democrática institucional, esto es, aquellos que se desarrollan en el marco de un proceso decisorio legalmente establecido y regulado, y que conducirá a tomar algún tipo de decisión jurídica en sentido amplio, y ii) en espacios de deliberación democrática no institucional, es decir, 
aquellos que se desarrollan amplia, difusa e informalmente en múltiples espacios y contextos de la esfera pública, que no están jurídicamente establecidos y no desencadenan una decisión jurídica. Sobre el particular, Martí afirma:

Los procesos deliberativos institucionales se regulan mediante derechos y obligaciones establecidos por otras normas jurídicas, y además están vinculados a los poderes del Estado. Los procesos deliberativos no institucionales, por su parte son procesos difusos, mucho más complejos y no reglamentados directamente por una norma jurídica, que tienen lugar en la esfera de la sociedad civil, con diferentes estructuras más o menos establecidas, diversa intensidad e importancia, etc., como la publicación de artículos de opinión, cartas al director en la prensa, los debates televisivos, las conversaciones de café, etc. En estos casos, no es posible determinar institucionalmente quién debe deliberar, así que los sujetos de la deliberación son potencialmente todos los seres humanos (2006, pág. 80).

Las democracias deliberativas requieren de estos espacios no institucionales, pues estos fortalecen el debate público. Sin embargo, estos espacios se han venido transformando sustancialmente como consecuencia de dos variables: la introducción de nuevas tecnologías a las interacciones entre los actores que participan en los procesos educativos y, 2) las transformaciones políticas que vienen afrontando las sociedades gracias a la cantidad y velocidad de información que está viajando con mayor facilidad y menores restricciones. ${ }^{3}$ Estas transformaciones

3 Said (2009, pág. 80) plantea al respecto: "El surgimiento de una nueva generación de estudiantes multimedia e hipertextuales, capaces han permitido pasar de una democracia representativa a un nuevo paradigma de democracia directa (Sauquillo, 2002, p. 285).

El presente documento plantea un modelo de educación cívica basado en el empleo de las tecnologías de la información y la comunicación (TIC), para lograr una comunicación masiva de saberes constitucionales que permitan una eficaz y cualificada deliberación democrática en sociedades interculturales. Los Estados de América Latina han empleado modelos conductistas de unificación cultural y cognitiva como mecanismo idóneo para lograr la culturización y civilidad de sus sociedades, desconociendo -o destruyendo- las diferentes manifestaciones culturales. Por esta razón, se analizará el papel que cumplen las tic en las sociedades occidentales democráticas actuales y, finalmente, se planteará cómo su uso contribuye a la comunicación eficaz de la educación cívica en sociedades democráticas, y por esta vía a la consolidación de una comunidad política más activa y pluralista. de establecer sus propias trayectorias individuales de construcción de acceso a la información y construcción del conocimiento, así como de alternar roles de lectura y autoría en escenarios virtuales, hacen que los avances TIc en los escenarios de enseñanza estén delineando un nuevo modelo de estudiante, cada vez más activo y constructivo, cada vez más responsable al momento de "acceder a la información, secuenciarla y extraer significados de ella" (Jonassen \& Grablinger, 1990, p. 4). Ello trae consigo la necesidad de replantear una reconfiguración del modelo pedagógico, así como la forma de aproximación que se hace en torno a las TIc y el perfil que deben tener los docentes para sacar el máximo provecho de este nuevo tipo de estudiante, miembro de la generación Bit o generación e." 


\section{EL PLURALISMO EN LAS DEMOCRACIAS DELIBERATIVAS}

¿Qué es el pluralismo en una sociedad democrática? En primer lugar, el pluralismo es un elemento fundamental en las sociedades modernas, pues en él se presenta la coexistencia de variedad de opciones religiosas, valorativas, políticas, filosóficas, científicas y de planes de vida dentro de una misma sociedad. Por ello, el pluralismo no hace más que expresar la complejidad y riqueza de la condición humana y el desarrollo de la autonomía y la libertad de los seres humanos. Como segundo aspecto, el pluralismo es diferente del concepto de tolerancia, aunque son complementarios:

Pues mientras que el primero subraya la variedad de grupos libres con igualdad de derechos, el segundo enfatiza la vigencia y la garantía de la libertad de los demás; mejor aún: el respeto de las concepciones y formas de comportamiento de los demás en su libre diferenciación. (Fernández, 1995, pág. 80). ${ }^{4}$

El pluralismo no debe confundirse con el multiculturalismo pues el segundo es solo una manifestación histórica del primero (Sartori, 2001, pág. 61). Ahora, la diferenciación entre multiculturalismo y pluralismo resulta importante dentro de la construcción de un modelo pedagógico intercultural para la educación cívica, pues mien-

$4 \quad$ "Ser tolerante implica respetar las creencias y opiniones de los otros y el reconocimiento de la diferencia y la diversidad de formas de vida. Por ello, la tolerancia es una actitud y una conducta especialmente importante para las minorías. La tolerancia no es lo mismo que indiferencia, ya que 'sobre todo somos tolerantes cuando esas diferencias nos importan'; tampoco la tolerancia significa 'indulgencia cómplice con crímenes y desafueros'." (Fernández, 1995, pág. 80). tras el primero aísla, el segundo está fundamentado sobre el valor de la tolerancia, contribuye a una convivencia pacífica, al reconocimiento del otro y al respeto de su identidad cultural: ${ }^{5}$

Así como la tolerancia es el rechazo de todo dogma, el pluralismo es, correlativamente, el rechazo de todo poder monocrático y uniformante (...) La ciudad moderna valora la disensión y, al valorarla, la civiliza, la modera, la transforma en un fermento beneficioso o incluso en una discordia que se convierte, al final, en acuerdo y concordia. Concordia. La "buena ciudad" del pluralismo se apoya, entonces, sobre una diversidad que produce integración, no desintegración... El multiculturalismo va en sentido contrario. En vez de promover una "diversidad integrada", promueve una identidad "separada" de cada grupo y a menudo la crea, la inventa, la fomenta. El resultado es una sociedad de compartimentos estancos e incluso hostiles, cuyos grupos están muy identificados consigo mismos, y por tanto no tienen ni deseo ni capacidad de integración. Como decía, el multiculturalismo no supera el pluralismo, lo destruye. (Sartori, 2009, pág. 124).

Ahora, el multiculturalismo no es un concepto que sea acorde con los principios y valores que

"El pluralismo no ha sido nunca un "proyecto". Ha surgido a trompicones de un nebuloso y sufrido proceso histórico. $\mathrm{Y}$ aunque sí es una visión del mundo que valora positivamente la diversidad, no es una fábrica de diversidad, no es un "creador de diversidades", una diversity machine. El multiculturalismo, en cambio, es un proyecto en el sentido exacto del término, dado que propone una nueva sociedad y diseña su puesta en práctica. $Y$ es al mismo tiempo un creador de diversidades que, precisamente, fabrica la diversidad, porque se dedica a hacer visibles las diferencias y a intensificarlas, y de ese modo llega incluso a multiplicarlas.

Por tanto, el multiculturalismo no es - como he subrayado en muchas ocasiones - una continuación y extensión del pluralismo sino que es una inversión, un vuelco que lo niega. Sobre todo en dos aspectos. El primero se refiere al nexo entre pluralismo, asociaciones voluntarias y grupos 'de adscripción'.” (Sartori, 2001, pág. 123). 
poseen las democracias deliberativas y pluralistas. Por esta razón, la sociología y la ciencia política han venido utilizando el concepto de interculturalidad, pues este:

No se limita a describir una situación particular, sino que define un enfoque, procedimiento, proceso dinámico de naturaleza social en el que los participantes son positivamente impulsados a ser conscientes de su interdependencia y es, también, una filosofía, política y pensamiento que sistematiza tal enfoque (Aguado, s. f., pág. 1). ${ }^{6}$

Es precisamente en este sentido que SchmeIkes (s. f., págs. 5-6) sostiene que el concepto de multiculturalismo resulta incompleto en la medida que pueden existir sociedades multiculturales en donde aún no haya interacciones culturales incluyentes sino que, por el contrario, estas siguen bajo marcos de discriminación y diferenciación:

A pesar de todo lo dicho hasta ahora, la multiculturalidad no acaba de satisfacernos. Se trata de un concepto descriptivo. Nos dice que en un determinado territorio coexisten grupos con culturas distintas. Pero el concepto no atañe a la relación entre las culturas. No califica esta relación. Y al no hacerlo, admite relaciones de explotación, discriminación y racismo. Podemos ser multiculturales y racistas... Por eso acudimos al concepto de interculturalidad. No se trata de un concepto descriptivo, sino de

6 Se utiliza el término educación intercultural con carácter normativo, para designar la naturaleza del proceso educativo deseable: "Podemos delimitarla como la referida a los programas y prácticas educativos diseñados e implementados para mejorar el rendimiento educativo de las poblaciones étnicas y culturales minoritarias $\mathrm{y}$, a la vez, preparar a los alumnos del grupo mayoritario para aceptar y aprender las culturas y experiencias de los grupos minoritarios." (Aguado, s. f., pág. 1). una aspiración. Se refiere precisamente a la relación entre las culturas y califica esta relación. La interculturalidad supone que entre los grupos culturales distintos existen relaciones basadas en el respeto y desde planos de igualdad. La interculturalidad no admite asimetrías, es decir, desigualdades entre culturas mediadas por el poder, que benefician a un grupo cultural por encima de otro u otros. Como aspiración, la interculturalidad forma parte de un proyecto de nación. (Schmelkes, s. f., pág. 5).

El concepto de interculturalidad se fundamenta en el respeto de la diversidad cultural y el reconocimiento de los derechos que poseen los diferentes actores que interactúan en los procesos democráticos. Así, las democracias que reconocen igualdad de derechos y garantías a sus habitantes no solo tienden a ser más garantistas per se de parte de las autoridades públicas, sino que la ciudadanía es consciente de los mecanismos de acción que posee para obtener la protección de sus derechos. Por ello, el reconocimiento de la interculturalidad no solo implica la existencia de la consagración de ese principio, sino su eficacia. Esto último es posible en espacios de diálogo como el generado en los procesos académicos. Por ende, los procesos pedagógicos en sociedades que reconocen normativamente la interculturalidad tienden a ser democráticos en términos de diálogo y reconocimiento de la diversidad del otro.

Las culturas no son entidades que se encuentren en el camino, sino que más bien se individualizan y adquieren unas características cuando alguien procede a describirlas, porque son construcciones borrosas sobre creencias que difícilmente se aproximan a una exhaus- 
tiva catalogación de todas y cada una de las creencias de todos los miembros de un grupo. (Beltrán, 2002, pág. 398).

Por eso, en el reconocimiento público de la ciudadanía es indispensable hacer una distinción entre dos formas de respeto:

En primer lugar, el respeto a la identidad única de cada individuo, independientemente de su raza, género o etnicidad; en segundo lugar, el respeto a aquellas actividades, prácticas o formas de ver el mundo que son objeto de una valoración singular y que son inseparables de los miembros de los grupos. (Beltrán, 2002, pág. 399).

El reconocimiento del pluralismo a nivel constitucional ha dado paso a una nueva etapa en pro de la inclusión y el respeto de las diferentes culturas, así como a la interacción entre estas. Este resultado ha sido producto de los valores y principios reconocidos en cartas de derechos modernas $^{7}$ que establecen la obligación del Estado de reconocer y proteger la diversidad étnica y cultural existente en sociedades pluralistas. Por ejemplo, la Corte Constitucional colombiana establece que del respeto a la diversidad étnica depende la convivencia armónica dentro de una democracia participativa (C-778 de 2005, M. Cepeda).

\section{LAS TIC EN LAS SOCIEDADES DEMOCRÁTICAS DELIBERATIVAS}

La aparición y evolución de las tic a finales del siglo XX han tenido consecuencias en todos los ámbitos de la vida social, entre ellas, la apertura de nuevas posibilidades, retos e incertidumbres para la democracia. En efecto, la masificación de la comunicación ha permitido a las sociedades conocer con mayor rapidez las actuaciones de los diferentes actores políticos, permitiendo a su vez ejercer un control sobre estos. ${ }^{8}$ Sin embargo, existen puntos de vista a favor y en contra del uso de las tic en los procesos democráticos. Sobre este punto, menciona Fuster (2012, pág. 12):

En el debate sobre internet y política pueden identificarse dos enfoques particularmente relevantes. Por un lado, un primer enfoque considera internet como un nuevo canal para los actores políticos y formas de participación existentes. En este enfoque, se considera que internet soluciona problemas actuales del sistema político y refuerza la democracia tal y como se entiende hoy. Por otro lado, un segundo enfoque caracteriza internet como un entorno, una esfera de relaciones sociales, con sus dimensiones económicas, políticas y culturales, las cuales todas juntas determinan qué formas organizativas pueden mantener-

8 Sobre este punto es importante mencionar cómo la exitosa campaña de Obama para la presidencia de los Estados Unidos en 2008 ha permitido replantear algunas posturas críticas sobre el papel de las TIC en las democracias. Efectivamente, como lo describe Fuster (2012, pág. 13), se ha presentado una revisión teórica junto con una "renovación del interés y confianza en las herramientas en línea para dar nuevo vigor a la política convencional (Gibson, 2009). Se considera que la adopción de la última generación de mecanismos de participación en línea multinteractivos fomenta la voz de los ciudadanos por encima de las élites establecidas (Surowiecki, 2005; Leadbeater, 2008)." 
se y cuáles deben ser cuestionadas. En este segundo enfoque, la cuestión gira en torno a qué sociedad está en formación en este entorno cambiante. Desde esta perspectiva internet no aparece como una "cura" para la democracia, sino como una fuente que, combinada con otros aspectos, podría llegar a transformarla.

Por otro lado, las TIc han ejercido una influencia considerable en las sociedades democráticas actuales, facilitando los procesos deliberativos entre ciudadanía y autoridades públicas, generando espacios directos para el debate y la reflexión política:

La incorporación de las tecnologías de la información y la comunicación en la política ha introducido cambios fundamentales en los sistemas políticos democráticos y ha supuesto nuevas posibilidades de relación entre los ciudadanos y los representantes políticos, permitiendo un cierto reencuentro entre la política y la sociedad. Las TIc pueden ayudar técnicamente a la mejora de los canales de información, comunicación, deliberación y participación de los ciudadanos en la toma de decisiones públicas, haciéndolos más inmediatos, sencillos y efectivos. Por otro lado permiten minimizar las limitaciones de tiempo y distancia que pueden afectar a la participación política, disminuyen los costes de organización de colectivos y aumentan las oportunidades de comunicación entre personas y de intercambio de contenidos (...) La comunicación que tenéis en las manos quiere estudiar la relación que se establece entre las TIC -sobre todo Internet-y la democracia, concretamente los mecanismos de participación ciudadana en la toma de decisiones públicas, acotando el estudio a la participación institucionalizada. A tal efecto, en primer lugar se observa su influencia en la democracia, explorando varias posibilidades en base al ámbito de aplicación de las tic y al grado de innovación democrática permitido. (Colombo, 2007, pág. 28).

La postura anteriormente expuesta es elemento esencial en la construcción de una democracia, pero no el más determinante en lo que a las TIC se refiere. En efecto, la construcción de una democracia más deliberativa con el uso de las TIC es posible porque a través de ellas se pueden adquirir elementos de juicio para tomar decisiones más conscientes y, por consiguiente, democráticamente más responsables. Por ello, las TIC cumplen una doble función en los procesos de construcción de democracias deliberativas: contribuir a brindar saberes al mayor número de personas posible (derecho a la educación), ${ }^{9}$ y con la comunicación de estos aportar elementos de juicio que permitan a la ciudadanía tomar decisiones democráticas de forma más responsable, para ejercer un control directo sobre los actores políticos mediante instrumentos formales o institucionales como los mecanismos de participación ciudadana o informales o no ins-

9

El cambio cualitativo y cuantitativo que caracteriza a la economía del saber, es la posibilidad de coproducción intensa de conocimientos por parte de diversos miembros de una comunidad -entendida como comunidad de intereses y no necesariamente ligada a un espacio físico común-, facilitada por la existencia de un espacio público de intercambio y circulación de saberes, y por la codificación y transmisión de nuevos conocimientos fuertemente basados en TIC. Así "una comunidad con una utilización intensa de conocimientos es una comunidad en la que una parte no desdeñable de sus miembros produce y reproduce el conocimiento cuyos límites se circunscriben a un espacio público (o semipúblico) de circulación de los saberes y en la que la utilización de nuevas tecnologías de información y comunicación ha reducido radicalmente el costo de codificación y distribución del conocimiento." (David y Foray, s. f., págs. 7 y 8). 
titucionales como las redes sociales. ${ }^{10}$ Sobre el particular menciona Colombo (2007, pág. 33):

\author{
La incorporación de las tic a la democracia ha \\ comportado un gran número de oportunidades \\ y límites para la política en general y para la \\ participación ciudadana en particular (...) Con \\ respecto a las oportunidades, destaca el hecho
}

10 Sobre el particular, Colombo (2007, págs. 77-78) menciona algunos casos: "En este marco de governance electrónica se potencian formas de participación electrónica diversas. En los años noventa encontramos en Estados Unidos y Europa algunas experiencias pioneras. Destaca Minnesota e-Democracy, nacida en 1994 con el objetivo de informar sobre los candidatos y los programas electorales.

Actualmente, se ha ampliado a Estados Unidos y permite a los ciudadanos debatir y opinar sobre temas políticos locales, estatales o federales. En el Reino Unido destaca UK Citizens Online Democracy, creada con el objetivo de ofrecer información y fomentar el debate entre los ciudadanos sobre temas de política general. A nivel local se desarrolla la experiencia Online Democracy in Brent, en la que además de la consulta a la ciudadanía también se ofrecía información y se abría el debate ciudadano.

En los últimos años estas experiencias se han desarrollado enormemente. Siguiendo la variable de alcance territorial destaca Vote for the EU you want, experiencia de ámbito supraestatal impulsada en el 2003 por la Unión Europea con el objetivo de aumentar la participación de los ciudadanos en los debates y la toma de decisiones. Permitía a los ciudadanos votar electrónicamente y emitir sus opiniones en relación con varios temas de interés para la UE.

A nivel autonómico encontramos Democracia.web, impulsada en 1998 por la Fundación Jaume Bofill con el apoyo del Parlamento de Cataluña, con el objetivo de acercar la ciudadanía al Parlamento. Permite a los ciudadanos comunicarse con los diputados y los grupos parlamentarios, seguir las tramitaciones parlamentarias y hacer llegar propuestas de enmienda. Por otro lado destaca la Web de l'Estatut, impulsada en el año 2004 por la Dirección General de Participación Ciudadana, con el objetivo de habilitar un espacio en Internet para el proceso de participación de reforma del Estatuto de Autonomía de Cataluña. Ofrecía información, varias herramientas de participación como foros de discusión, chats y la posibilidad de realizar preguntas y propuestas sobre la nueva ley estatutaria.

En el ámbito municipal encontramos Consensus, experiencia que ofrece varias funcionalidades de participación ciudadana a los municipios, con tal de complementar los procesos participativos presenciales. También a nivel local, encontramos Madrid Participa, la consulta ciudadana electrónica con más participantes potenciales (136.227 personas) realizada en España. Tiene lugar en Madrid en junio del 2004 y a través de las TIC y centros presenciales realiza una consulta sobre posibles actuaciones y mejoras en equipamientos que debería promover el Ayuntamiento en el distrito de Centro.

Es preciso señalar que las experiencias mencionadas se encuentran dentro de la estrategia demoelitista, introduciendo cambios en el elitismo democrático sin alterar la lógica de la representación." de que Internet tiene su principal función en ser un elemento de información y comunicación. ${ }^{11}$ En este sentido, la red tiene la potencialidad de aumentar la información de los ciu-

11 Fuster menciona algunas posturas conceptuales que relativizan el postulado informativo de las TIC. Sobre el particular menciona el autor de la referencia: "En el debate sobre internet y política pueden identificarse dos enfoques particularmente relevantes. Por un lado, un primer enfoque considera internet como un nuevo canal para los actores políticos y formas de participación existentes. En este enfoque, se considera que internet soluciona problemas actuales del sistema político y refuerza la democracia tal y como se entiende hoy. Por otro lado, un segundo enfoque caracteriza internet como un entorno, una esfera de relaciones sociales, con sus dimensiones económicas, políticas y culturales, las cuales todas juntas determinan qué formas organizativas pueden mantenerse y cuáles deben ser cuestionadas. En este segundo enfoque, la cuestión gira en torno a qué sociedad está en formación en este entorno cambiante. Desde esta perspectiva internet no aparece como una "cura" para la democracia, sino como una fuente que, combinada con otros aspectos, podría llegar a transformarla.

Dentro de la primera perspectiva, según Koopmans y Zimmermann (2003), el debate sobre el efecto potencial de internet en la política y la democracia ha estado desde el principio dominado por el enfrentamiento entre perspectivas escépticas y optimistas (della Porta y Mosca, 2006), utopías y distopías (Silver, 2000), deterministas tecnológicos y deterministas sociales (Vaccari, 2009), teóricos de la movilización y teóricos del refuerzo (Norris, 2002). Los hay quienes proclaman que internet no tiene efectos relevantes en la política y en la democracia. La hipótesis de la normalización predice que la política seguirá siendo "política como siempre», y que las relaciones de poder no se verán cuestionadas por los usos de internet (Mosca, 2007). Otros estudios más recientes se sitúan en posturas más intermedias. Para Bimber (2003), los cambios asociados a los usos de internet pueden crear ventajas para ciertas formas de organización y estructura, y desventajas para otras, que lleven a la adaptación y al cambio en el mundo de las organizaciones e intermediarlos políticos. El uso de internet podría tanto fortalecer como debilitar la democracia.

El enfoque de efectos se caracteriza sobre todo por considerar los cambios como complementarios a las instituciones políticas actuales en las democracias representativas. Pueden diferenciarse dos áreas principales de aplicabilidad en el seno de la perspectiva de efectos: el uso de internet para reforzar componentes clave del proceso político (como el voto y las campañas electorales) (Trechsel, 2007) y el uso de nuevas tecnologías de la información y la comunicación (TIC) para mejorar la administración pública y hacer más accesible la política profesional. Es decir, el uso de TIC para mejorar la calidad de los servicios de una administración, comenzando con una mayor accesibilidad a la información y la puesta en marcha de gestión en línea en un sentido consumista, según las pautas de las propuestas realizadas por la Escuela de la Nueva Gestión Pública (New Public Management School) desde la década de 1980 (Hughes, 2003). Las TIC se usan también con el propósito de acercar al ciudadano a las élites políticas, para facilitar el conocimiento y el contacto con los parlamentarios y/o actores públicos (Subirats, 2002). No obstante, algunos autores señalan de qué modo las TIC cuestionan los principios fundamentales de la nueva gestión pública (Dunleavy et al., 2005)." (Fuster, 2012, pág. 20). 
dadanos sobre cuestiones políticas, promover la educación democrática de la ciudadanía, permitir la comunicación entre los ciudadanos y sus representantes y aumentar su interés en la política. En relación con la participación ciudadana, permite una distribución más eficiente de la información y la documentación política relevante para los procesos participativos permitiendo una participación más informada. En segundo lugar, permite superar las distancias existentes entre ciudadanos y políticos propias de las democracias representativas en una comunicación bidireccional e interactiva que posibilita la publicitación de intereses, valores y opiniones de ciudadanos hacia otros ciudadanos y hacia las instituciones." 12

En relación con este aspecto, menciona Mochi (2001): "No ignoraremos para desarrollar esta línea de investigación estudios ya hechos sobre estas experiencias como son: existen algunos gobiernos locales que ya han realizado esfuerzos importantes para la implementación de páginas web que permiten el acceso de la ciudadanía a la información y facilitan a su vez una herramienta de comunicación con los funcionarios representantes políticos electos a través del correo electrónico: es el caso de la ciudad de Austin (Texas) en EE. UU.; la ciudad de Buenos Aires (Proyecto del Consejo Deliberante) en Argentina, los Centros de Gestión y Participación del gobierno de la ciudad de Buenos Aires, en Argentina (CGP). Otros niveles son el rol de las organizaciones de la sociedad civil en la implementación de telecentros que han permitido un uso público de internet así como su enseñanza de utilización por parte de la ciudadanía. Muy importante en este aspecto es la experiencia de Perú.

En Senegal, la liberación de la normativa en materia de telecomunicaciones ha dado lugar a la proliferación de "telecentros", que ofrecen a los ciudadanos acceso a las telecomunicaciones brindado una cantidad enorme de servicios y creando miles de puestos de trabajo

En Sudáfrica, también el crecimiento de este tipo de centros permitió alcanzar tasas de acceso a los servicios públicos, sin precedentes, así como brindar una información esencial sobre asistencia sanitaria, educación y otros servicios sociales.

Si bien ya existe un vínculo estrecho entre nuevas tecnologías y democracia, todavía está todo por desarrollarse. Por el momento darle a esta posibilidad el nombre de "democracia electrónica", es pensar en la democracia ateniense, donde una pequeña élite tiene acceso a esta extraordinaria forma de información y participación política."

\section{LAS TIC Y LA EDUCACIÓN CÍVICA}

La Constitución política es para todos los habitantes del Estado, quienes a su vez deben conocerla, interiorizarla y vivificarla (De Antonio Gómez, 2001, pág. 11). Por ende, una carta de derechos requiere ser conocida por el mayor número de integrantes de un Estado para convertir en realidad sus postulados. Y la educación cívica juega un papel fundamental en la consolidación de los presupuestos constitucionales. De esta manera, el proceso de consolidación democrática genera los necesarios debates que exige toda sociedad políticamente activa. Así, Häberle (2003, pág. 190) considera que “la Constitución debe (poder) ser autocrítica respecto de sus propios fines educativos". Así mismo, los procesos educativos en materia constitucional deben contribuir a generar espacios de deliberación social, diferentes a los institucionales (Parlamento, tribunales constitucionales, etc.) en los cuales la ciudadanía interactúe en aras de consolidar los presupuestos democráticos consagrados en la Constitución.

El mandato constitucional no exige en stricto sensu la transmisión de conocimientos jurídicos-teóricos, pues esto es cosa del "gremio" de los juristas. Al contrario, la norma jurídica pretende es que la Constitución sea comunicada como marco y afirmación de los ideales de la educación: "La Carta Política es texto escolar y docente. Su realidad comienza en los salones de clase: ¡la escuela de la Constitución es la escuela! Lo que ésta logre beneficia a la cultura constitucional” (Häberle, 2003, pág. 190). Por 
ello, esta vía pedagógica hacia una Constitución eficaz no puede ser sobreestimada en su relevancia jurídica mediata y su eficacia a largo plazo. La escuela, la universidad, las escuelas profesionales y la enseñanza para los adultos forman a los intérpretes constitucionales en sentido amplio. La relación entre los planes de estudio y la Constitución se hace lo más estrecha posible; en sentido amplio se trata de "clases de Constitución".13 La educación cívica es necesaria para lograr una sociedad democrática, pluralista y humanista (CConst., T-179 de 2000. A. Martínez). En tal virtud, el Estado Social de Derecho adquiere una enorme dimensión cuando la educación constitucional forma a ciudadanos en el respeto a los derechos humanos, a la paz y la democracia.

El pluralismo y la libertad educativa deben respetar y promover al máximo dos valores fundamentales en el objetivo del proceso educativo: la democracia y el libre desarrollo de la personalidad humana. En tal sentido, en todas las instituciones de educación se deben fomentar prácticas democráticas para el aprendizaje de los principios y valores de la participación ciudadana. Así, una idea de democracia militante recorre la Constitución y, conforme a ella, Ios actores del proceso educativo han de comenzar a experimentarla como una de sus vivencias más próximas y formadoras. ${ }^{14}$

13 El artículo 41 de la Carta Política establece: "En todas las instituciones de educación, oficiales o privadas, serán obligatorios el estudio de la Constitución y la instrucción cívica. Así mismo se fomentarán prácticas democráticas para el aprendizaje de los principios y valores de la participación ciudadana. El Estado divulgará la Constitución."

14 "La democracia, como diálogo social y búsqueda cooperativa de la verdad, requiere que las personas, desde los bancos escolares, sean
El modelo educativo que quiera convertirse en simiente de una sociedad abierta deberá propender porque los actores sociales que participan en el proceso educativo actúen decididamente en la comprensión y resolución de los problemas y conflictos que a menudo surgen en el ámbito escolar, aplicando parámetros de diálogo y reconocimiento de los derechos que poseen cada uno de ellos. En este aspecto, las TIC jugarían un papel importante en los procesos de educación cívica, pues la facilidad e interacción que estas brindarían en la promoción de los valores democráticos, inclusive en contextos virtuales, garantiza "el reconocimiento de la necesaria igualdad de oportunidades enmarcadas en la Sociedad de la Información de la que hacemos parte" (Said, 2009, pág. 80).

Ahora bien, en materia de educación el concepto de interculturalidad resulta ser de bastante importancia dentro del proceso de reconocimiento del pluralismo. Por ejemplo, en Colombia durante la vigencia de la Constitución centenaria de 1886, las propuestas educativas estaban orientadas a un proceso de integración a los patrones de vida de la mayoría de la sociedad nacional y, por tal razón, estas siguieron siempre los principios y objetivos básicos de la educación general. Con la expedición de la Constitución de 1991, al definirse el Estado colombiano como democrático y pluralista, se abandonó por completo la idea integracionista y se le impuso al Estado la obligación de adop-

conscientes de sus derechos y deberes y tengan oportunidades de ejercitarlos activa y responsablemente mediante el trabajo en equipo, el respeto a los otros y el ejercicio constante de la solidaridad y la tolerancia." (CConst., T-337 de 1997, C. Gaviria). 
tar para estas comunidades étnicas un sistema educativo diferente al de la mayoría, que sea acorde con sus particulares características. Por ejemplo, la ley general de educación (Ley 115 de 1994) consagra el concepto de etnoeducación, definiéndolo como la educación "que se ofrece a grupos o comunidades que integran la nacionalidad y que poseen una cultura, una lengua, unas tradiciones y unos fueros propios y autóctonos", la cual además “debe estar ligada al ambiente, al proceso productivo, al proceso social y cultural, con el debido respeto de sus creencias y tradiciones" (art. 55). Asimismo, el señalado ordenamiento se refiere a los principios y fines que orientan la etnoeducación, destacando como especialmente relevantes los de integralidad, interculturalidad, diversidad lingüística, participación comunitaria, flexibilidad y progresividad, cuya finalidad es la de afianzar los procesos de identidad, conocimiento, socialización, protección y uso adecuado de la naturaleza, así como también los sistemas y prácticas comunitarias de organización, uso de lenguas vernáculas, formación docente e investigación en todos los ámbitos de la cultura (art. 56). ${ }^{15}$ Es por ello que el ordenamiento jurídico

15 Dicho estatuto consagra el bilingüismo para la enseñanza de los grupos étnicos con tradición lingüistica propia, tomando como fundamento la lengua materna del respectivo grupo (art. 57); le asigna al Gobierno Nacional, a través del Ministerio de Educación y en concertación con los grupos étnicos, la función de prestar asesoría especializada en el desarrollo curricular, elaboración de textos y materiales educativos, y, especialmente, en la ejecución de programas de investigación y capacitación etnolingüística (art. 59); prohíbe la injerencia de los organismos internacionales en la educación de los grupos étnicos, sin la previa aprobación del Gobierno y el consentimiento otorgado por las comunidades interesadas (art. 60); y ordena que de ser necesaria la celebración de contratos para la prestación del servicio educativo de las comunidades tradicionales, estos deben ajustarse a los principios y fines de la etnoeducación y su ejecución deberá ser concertada con las autoridades indígenas de las respetivas entidades territoriales (art. 63). nacional les impone a las autoridades públicas compromisos concretos:

- Promover y fomentar tanto la formación de educadores en el dominio de las culturas y lenguas de los grupos étnicos como también los programas sociales para su difusión (Ley 115 de 1994, art. 58).

- Seleccionar a los educadores que laboren en los territorios de los grupos étnicos, en concertación con tales grupos, prefiriendo escogerlos de entre los miembros de las comunidades en ellas radicados; debiendo verificar, además, que dichos educadores acrediten formación en etnoeducación y posean conocimientos básicos del respectivo grupo étnico, en especial de su lengua materna, además del castellano (Ley 115 de 1994, art. 62).

- Efectuar la vinculación, administración y formación de docentes para los grupos étnicos de "conformidad con el estatuto docente y con las normas especiales vigentes aplicables a tales grupos" (CConst., C-208 de 2007, R. Escobar).

\section{LA EDUCACIÓN CÍVICA INTERCULTURAL PARA SOCIEDADES DEMOCRÁTICAS DELIBERATIVAS}

Los patrones pedagógicos deben ser acordes con las transformaciones sociales que afrontan las comunidades que interactúan en los procesos de aprendizaje..$^{16}$ De esta forma, la educación cívica debe adaptar dos elementos: 1) la

\footnotetext{
16 Para Ortiz (2009, pág. 25), un modelo pedagógico es la "construcción teórica y formal que fundamentada [de manera] científica e ideológica [sic] la interpretación, diseño y ajuste de la realidad pedagógica respondiendo a una necesidad histórica concreta".
} 
gran demanda de parte de la ciudadanía de una eficaz garantía de sus derechos fundamentales y el ejercicio de sus derechos políticos y, 2) la rápida circulación de información que se presenta gracias a los avances tecnológicos que existen en la sociedad contemporánea. Ahora, la adaptación de estos elementos permitiría una interacción en criterios de igualdad de derechos entre los actores del proceso educativo. Igualmente, los procesos educativos de educación cívica deben ser espacios de deliberación argumentativa, dado que no solo se comunican conocimientos democráticos, sino que deben preparar a los participantes para los futuros procesos deliberativos. Por ello, la educación cívica no puede basarse en modelos conductistas, ${ }^{17}$ pues estos restringen el diálogo entre los participantes al ubicar al docente como detentador del conocimiento y al estudiante como carente de saber. ${ }^{18}$

17 "La relación del conductismo con las TIC está soportada a través del siguiente análisis: La relación sujeto-medio externo en el conductismo, dentro del contexto de las TIC aplicadas a la educación, implica que los sistemas componentes de las áreas de la informática y las comunicaciones, con base en el enfoque pedagógico y la didáctica utilizada en el ambiente virtual a través de las actividades de enseñanza, estimulan al sujeto de quien el espacio virtual espera una respuesta. Respuesta que recibe un esfuerzo positivo o negativo (en un proceso de evaluación de una unidad compuesta por pretest, test y postest, un refuerzo positivo es aprobar una unidad de conocimiento, cuando el alumno pasa el pretest de dicha unidad de conocimiento virtual), y un refuerzo que afecta la conducta del sujeto, cuando sigue interactuando con el espacio de formación virtual durante su proceso de aprendizaje." (Capacho, 2011, p. 79).

18 Para Trujillo (2008, pág. 136): "Este modelo pedagógico, fruto de la racionalidad instrumental, de la racionalización y planeación económica de los recursos en la fase superior del capitalismo (Flórez, $1997,167)$, sostiene que la conducta de los estudiantes puede ser moldeada según las necesidades de los procesos productivos técnicos. Su método puede desarrollarse en función de la consecución de objetivos previamente definidos en términos operacionales, por medio del reforzamiento de aquellas conductas que más se aproximen al comportamiento esperado. En este esquema el conocimiento se define como conducta observable y los contenidos del proceso educativo tienen que ver con destrezas y habilidades propias de los procesos técnicos.
Adicionalmente, el modelo conductista resulta contrario a los procesos deliberativos por desconocer la igualdad que existe entre los actores y sus argumentos, pues considera al docente como superior cognitivo del estudiante. Por esta razón, De Zubiría (2006, pág. 194) considera importante que los procesos de educación cívica deben basarse en "un modelo dialogante e interestructural (Not, 1983), que reconozca tanto el papel activo del estudiante en el aprendizaje como el rol esencial y determinante de los mediadores en este proceso, es decir, un modelo que garantice una síntesis dialéctica."19 Por ello, el uso de un modelo pedagógico que acepte las diferencias, que fomente el respeto por las ideas ajenas (más cuando estas no son

La relación P-A que supone la meticulosa programación del proceso de enseñanza-aprendizaje, no puede ser descrita solamente como vertical y autoritaria, sino que podría llamarse incluso "dictatorial", en la medida en que el alumno no sólo no tiene la menor posibilidad de participar en la formulación de los planes de enseñanza, sino que tampoco menos puede discutirlos. La idea de desarrollo como un proceso cuantitativo de acumulación de aprendizajes, hace que para este modelo aprendizaje y desarrollo sean sinónimos, razón por la cual se concibe la evolución como un continuo, carente de crisis o conflictos, de etapas o fases. Así, el profesor debe cumplir su papel de operario que ejecuta las técnicas prediseñadas por quienes definieron las instrucciones y los objetivos. Este papel es moralmente aséptico pues en las metas se percibe un marcado relativismo moral." [Cursivas fuera del texto].

19 "Hay que reconocer que el conocimiento se construye por fuera de la escuela, pero que es reconstruido de manera activa e interestructurada a partir del diálogo pedagógico entre el estudiante, el saber y el docente y que, para que ello se presente, es condición indispensable contar con la mediación adecuada de un maestro, que favorezca de manera intencionada, mediada y trascendente el desarrollo integral del estudiante. Un modelo que concluya que la finalidad de la educación no puede estar centrada en el aprendizaje, como desde hace siglos ha creído la escuela, sino en el desarrollo.

Hoy en día, un modelo pedagógico dialogante debe reconocer las diversas dimensiones humanas y la obligación que tenemos escuelas y docentes de desarrollar cada una de ellas. Como educadores, somos responsables del desarrollo de la dimensión cognitiva de nuestros estudiantes; pero tenemos iguales responsabilidades en la formación de un individuo ético que se indigne ante los atropellos, se sensibilice socialmente y se sienta responsable de su proyecto de vida individual y social." (De Zubiría, 2006, págs. 134 y 135). 
las adoptadas por la mayoría de los miembros dentro del proceso educativo) resulta fundamental en procesos de educación cívica dirigidos a preparar ciudadanos para participar en procesos democráticos deliberativos. De esta forma es posible materializar los presupuestos constitucionales que conlleven a una democracia eficaz. ${ }^{20}$

Ahora, la educación cívica en sociedades pluralistas debe partir del supuesto que todos los actores son seres sociales $-y$ políticos-, pero que un número considerable de estos no tienen claros sus derechos y deberes como integrantes del Estado. Por ello, según De Zubiría (2006), el diagnóstico de las fortalezas y debilidades de los actores del proceso educativo acerca del conocimiento de sus derechos y deberes democráticos resulta metodológicamente necesario (pág. 218); de ahí la importancia de identificar las cualidades de los actores -así como sus competencias ciudadanas- para apoyarlos, orientarlos y desarrollarlos para "hacer que la fortaleza de hoy se consolide mañana, por su propio beneficio y por el beneficio colectivo y social" (pág. 218). De la misma forma, una educación cívica dialogante permite una mayor interacción entre los actores, fortaleciendo la comunicación y praxis de los valores democráticos y fomentando la participación y el diálogo,

20 En efecto, y de acuerdo con lo planteado con Said (2009, pág. 81): "El paso del modelo pedagógico literario al hipermedia trae consigo la adaptación de los contextos de enseñanza hacia contextos de aprendizaje en los que los estudiantes participan, activamente, en la construcción del pensamiento no lineal, desde los escenarios virtuales de acceso a la información y conocimiento dispuestos en la actualidad, así como a través de la inclusión de hipertextos en los contenidos y en la construcción de formas de comunicación asincrónicas." herramientas fundamentales para el aprendizaje de los valores democráticos. ${ }^{21}$

Adicionalmente, la educación cívica para sociedades democráticas deliberativas debe tener presente dos factores: 1) la interculturalidad de los actores como valor democrático y, 2) las TIC como espacio de interacción. La interculturalidad es una característica de sociedades pluralistas. Por esta razón, para brindar una educación cívica intercultural deberían tenerse unos parámetros en materia tanto de contenidos temáticos como de diseño de las estrategias pedagógicas a emplear: a) una perspectiva inclusiva que observe como necesidad la generación de espacios en donde interactúen todos los actores y no solo las minorías étnicas, ${ }^{22}$ b) resal-

21 "Una participación, eso sí, que promueva el debate de ideas con sólidas argumentaciones y no con meras opiniones. Una escuela del diálogo que provoque preguntas; abierta al respeto crítico y activo y no a la mera tolerancia pasiva; sensible tanto a la libertad como a la igualdad, un binomio inseparable; que fomente la colaboración y la autonomía; y que se convierta en un espacio permanente de opinión refrendada con argumentos, no en una simple "opinionitis"." (Carbonell, 2005, pág. 26)

22 "Nunca me ha gustado la expresión derechos de las minorías, porque da la impresión de significar un tipo de derechos especiales para personas especiales, al margen de la idea de los derechos fundamentales como derechos de todos los seres humanos. Es decir, da la impresión de que las minorías piden un trato particular o especial cuando de lo que se trata básicamente es de la exigencia de un trato igual. Desde la perspectiva de los derechos humanos, una vez conquistado y reconocido el derecho a una y la misma igualdad de trato o respeto sin discriminaciones, podemos darnos por satisfechos. Se puede seguir hablando de derechos de las minorías, siempre que un sector de población no cuente con las mismas oportunidades morales, políticas y jurídicas que la mayoría, y hasta el momento en que el Ordenamiento Jurídico garantice la igualdad de todos en el ejercicio de los mismos derechos. Sin embargo, el hecho real es que existen sectores de la población que se sienten discriminados en cuanto al trato recibido por la sociedad, el sistema político o el Derecho, y la única razón de ese trato distinto se encuentra en que expresan algún tipo de diferencia en relación con los otros o con la mayoría. Pues bien, parece justificado mantener que un sistema democrático, en este caso la Europa democrática, debe ser especialmente generoso en el reconocimiento de la diversidad y de los particularismos culturales y debe trabajar con rapidez y eficacia para lograr el objetivo de la igualdad moral, política y jurídica, de la igualdad en el disfrute de los 
tar la diversidad como un valor y no como una deficiencia u elemento a eliminar $y, c)$ reformas educativas ${ }^{23}$ tendientes a conseguir mejorar los estándares de calidad en la educación que deben recibir todos. Ahora, estos parámetros son realizables con la obtención de objetivos concretos que resultan concretizados eficazmente con el uso de las tic y con el empleo de estrategias dinámicas que faciliten el mayor intercambio de saberes entre los actores del proceso educativo: ${ }^{24}$

- Incentivar la equidad educativa, es decir, una educación en igualdad de oportunidades para que todos los actores ${ }^{25}$ logren desarrollar al máximo su potencial, sin pretender la obtención de iguales resultados, sino que las diferencias que se encuentran entre ellos no sean debidas a factores sociales, culturales o económicos.

- Superar el racismo, la discriminación y la exclusión. ${ }^{26}$

- Favorecer la comunicación y competencias interculturales. ${ }^{27}$

- Apoyar el cambio social según principios de justicia social. ${ }^{28}$

La realización de los objetivos mencionados permitiría no solo mejorar la calidad académica (lo que preocupa a los gobiernos de economías en progreso), sino objetivar la propia identidad y

26 Para ello, es necesario desnaturalizar la situación de exclusión, promoviendo el cuestionamiento y la comprensión de las causas que contribuyen a que se produzcan situaciones de injusticia y de privación de derechos fundamentales, es decir, hacer visible lo que la mirada unificadora pretende ocultar.

derechos humanos sin distinción entre mayorías y minorías. Creo, por tanto, que conviene perfectamente el derecho a ser minoría, que es el derecho a ser, a pensar, expresarse y obrar de manera diferente o particular, con el derecho a no ser tratado como minoría, es decir, con el derecho a ser iguales en derechos que la mayoría. Pero estamos aún bastante lejos de que sea una auténtica realidad esa convivencia, aunque es un objetivo irrenunciable de la futura Europa democrática. Ahora es el momento de tratar el tema de los medios ideológicos, políticos y jurídicos para lograr esa protección de las minorías. Creo que en una Europa democrática no habrá necesidad de pedir a las minorías que renuncien a sus particularismos y diferencias, ni tampoco a los demócratas excesivos sacrificios en la defensa de su sistema de libertades y de su concepción de lo justo.” (Fernández García, 1995, págs. 77 y 78).

23 Entiéndase escuela no como el espacio, sino como el espacio social donde se construye el conocimiento. Por ello, se incluye tanto la formación básica (primaria y secundaria), la media vocacional y la educación superior (técnica, tecnológica, profesional y postgradual).

24 Estas estrategias deben aplicarse desde los primeros momentos en que el niño o niña empiezan a interactuar con los demás integrantes de la sociedad. Así, el nivel preescolar permite "la expresión de la propia identidad convirtiéndose en un paso necesario para la comprensión de la identidad del otro." (Schmelkes, s. f., pág. 8).

25 Para el trabajo, la categoría de actores se encuentra conformada por aquellas personas que desempeñen cualquiera de estos roles: docentes, administrativos, estudiantes y padres de familia.
27 Los actores competentes interculturalmente serán aquellos que tengan la habilidad de interactuar con los demás, aceptando otras perspectivas y percepciones del mundo, de mediar entre diferentes perspectivas y de ser conscientes de sus propias valoraciones sobre la diversidad. La competencia intercultural se compondría de conocimientos, habilidades y actitudes, complementados por los valores que cada uno tiene por su pertenencia a una sociedad y a unos grupos sociales determinados. Las actitudes (apertura, voluntad de flexibilizar las propias creencias y comportamientos, empatía, entre otros) constituirían la base de esta competencia.

28 "La meta de la educación para la interculturalidad es transformar la sociedad en un espacio más justo y democrático en donde la escuela juega un papel fundamental en el cambio social y educativo, pues ahí es donde los actores pueden interactuar como seres culturales. Las instituciones educativas se encuentran en una posición favorecida para incentivar la transformación social, de modo que en ella es posible superar las desigualdades (racismo personal e institucional, etnocentrismo, desigual distribución de recursos, relaciones de poder desiguales, etc.), sin que se presenten agresiones entre los actores. Para ello, es necesario que la escuela transforme su orientación hacia la valoración y aceptación de la diversidad cultural como un elemento positivo para todas las personas que en ella interactúan. De igual manera, es necesaria la formación de profesores para la interculturalidad que apliquen metodologías en el aula y en el clima escolar que tiendan al intercambio de valores culturales que posean todos los actores. Esto se complementa con la extensión de la propuesta educativa a todos los ámbitos sociales y no sólo al educativo." (Leiva y Muñoz, 2014, pág. 20). 
respetar e interactuar con la del otro. ${ }^{29} \mathrm{Al}$ mismo tiempo, la perpetración de estos objetivos "permite aprender a escuchar lo ajeno, a respetarlo y a apreciarlo. Son hábitos que se traducen en habilidades y valores. Se traducen en la curiosidad por conocer lo diferente y por valorar la diversidad, incluida la diversidad cultural." (Schmelkes, s. f., pág. 9).

\section{En concordancia con lo anterior, la incorporación} de las tic en la educación cívica debe atender a la realidad cultural de los estudiantes, respetar su diversidad y promover su identidad cultural. ${ }^{30}$ En la realidad intercultural:

La reflexión sobre cómo las tic pueden contribuir al respeto, la defensa y el conocimiento mutuo de las diferentes culturas, aspectos que se convierten en una exigencia ineludible para una democracia, independientemente del ni-

29 "El diálogo con otras identidades puede y debe perseguirse tanto de manera directa — con las diferencias individuales presentes en cada aula - como de manera indirecta, conociendo acerca de otras identidades. Es esencial trabajar el reconocimiento del otro como distinto, lo que se obtiene en este nivel mediante el trabajo sistemático con hábitos de respeto hacia los compañeros, haciendo conciencia de las características particulares de cada uno de ellos." (Schmelkes, s. f., págs. 8 y 9 ).

30 "Por eso en el reconocimiento público de la ciudadanía es indispensable hacer una distinción entre dos formas de respeto: en primer lugar, el respeto a la identidad única de cada individuo, independientemente de su raza, género o etnicidad; en segundo lugar, el respeto a aquellas actividades, prácticas o formas de ver el mundo que son objeto de una valoración singular y que son inseparables de los miembros de los grupos. La petición de los multiculturalistas es el reconocimiento de esta segunda forma de respeto particular por encima de la primera forma de respeto, la genuinamente liberal, la que supone el reconocimiento de la identidad más universal de las personas como merecedoras de respeto y sujetos de derechos, libertades y oportunidades, simplemente por el hecho de ser personas. La valoración liberal de la diversidad y de la apreciación de las culturas desconfía de la exigencia de políticas conservacionistas para culturas y subculturas que no prosperarían mediante la libre asociación de los ciudadanos. El liberalismo, las democracias liberales en concreto, defienden y valoran la diversidad desde una perspectiva universalista, no desde el particularismo multicultural (Gutmann, 1993, pp. 21-23)." (Beltrán, 2002, págs. 398 y 399). vel de complejidad en su realización, toda vez que la cultura occidental [pretende] ser absolutamente hegemónica en este campo (Díaz, 2012, pág. 164 ).

Por esta razón, las tic deben ser un espacio de interacción para los procesos de educación cívica en sociedades democráticas pluralistas e interculturales, facilitando la comunicación y práctica de la educación cívica:

Existe un amplio acuerdo sobre la capacidad de las nuevas tecnologías para "romper" las barreras espaciales y temporales, dotando de un nuevo significado a los conceptos de espacio y tiempo, y posibilitando que el aprendizaje se produzca en cualquier lugar y momento (...) Esto pone el acento en la necesidad de llevar a cabo un cambio de escenario que suponga desplazar el foco de atención y estudio de la escuela a la sociedad. Como señaló Durkheim (2000), la educación es principalmente un proceso de socialización, de adquisición de habilidades y pautas de conducta social que tiene lugar en el seno de diversos grupos. Y por ello, se podría añadir, si es la sociedad la que educa, debe estar involucrada y participar de las decisiones que se adopten en materia de educación. Lograr implicar a la sociedad tomando en cuenta su opinión no supone garantizar el éxito ni reduce el riesgo, pero permite consensuar las decisiones $y$, en cierta forma, reducir el impacto social de los errores.

Esta implicación y apoyo social conlleva la necesaria participación de nuevos actores en la acción educativa, en especial de las familias y de los municipios. Como se señaló en un apartado anterior, si el contexto familiar es uno de los factores determinantes del progreso educa- 
tivo, es imprescindible mejorar su formación y su nivel cultural. Por ello, lograr que las familias se acerquen a las nuevas tecnologías permitirá una mayor aproximación a la cultura de sus hijos y a su forma de aprender (...) Por otro lado, el municipio puede convertirse en el marco principal que permita potenciar la coordinación de los distintos sectores relacionados con la educación, en especial aquellos situados en zonas rurales con menor acceso a la educación y a la cultura. Impulsar programas integrales que incorporen las TIC como herramientas de formación y trabajo puede ser una estrategia fundamental para lograr este propósito. (Díaz, 2012, pág. 160).

Estos presupuestos deben adelantarse en sociedades democráticas pluralistas que deseen masificar sus procesos de educación cívica. Para ello, la generación de espacios virtuales de aprendizaje (EVA) resulta apropiada para generar espacios deliberativos a través de tıc, pues estos se encuentran diseñados "para facilitar la comunicación pedagógica entre los participantes en un proceso educativo, sea éste completamente a distancia, presencial, o de una naturaleza mixta que combine ambas modalidades en diversas proporciones" (Silva 2011, pág. 63) y que haga uso de estrategias pedagógicas tales como materiales educativos en formato digital (textos, imágenes, audio, simulaciones, etc.), debates en línea y la integración de contenidos relevantes de la red para posibilitar la participación de expertos o profesionales externos a través de foros interactivos. ${ }^{31}$

31 Sobre este aspecto menciona Silva (2011, pág. 63): "Un Entorno Virtual de Aprendizaje es un espacio diseñado con finalidades formativas: debe diferenciarse de un espacio web bien estructurado, pues éste no garantiza aprendizaje. El diseño debe nutrirse principalmente de las

\section{CONCLUSIONES}

En primer lugar, los iusfilósofos actuales entienden que los ciudadanos y ciudadanas de un país tienen el deber de deliberar responsablemente entre sí acerca de sus leyes y de las reglas de convivencia que se imponen. Todos tienen ese deber, de manera que han de tratar de llegar a acuerdos con los demás para construir los marcos legales necesarios para asegurar la paz y la seguridad, resolver los conflictos, impartir justicia y mejorar sus condiciones de vida, es decir, tienen un deber de participación cívica que puede ser formulado de modos diferentes, pero cuyo contenido tiene que ver con la posibilidad de existencia de una concepción de ciudadanía. Por esta razón, las sociedades democráticas actuales son aquellas que van más allá del contenido de las leyes, pues se fundamentan en que los ciudadanos sean capaces de cooperar con los demás, de escuchar y de deliberar en las discusiones con el fin de alcanzar compromisos:

Importa que los habitantes de ese Estado se comporten como ciudadanos porque difícilmente se puede lograr una sociedad justa si cada uno únicamente tiene en cuenta los intereses propios y el interés público no ocupa ningún lugar en las deliberaciones acerca de las decisiones de las personas. (Beltrán, 2002, pág. 399).

En segundo lugar, las propias instituciones ejercen una influencia directa sobre las creencias

investigaciones relacionadas con la estructuración y representación de la información y cómo puede ser utilizada en actividades de aprendizaje e interacción." 
y motivaciones de la ciudadanía, bien sea para facilitar o para restringir espacios políticos de cualidades deliberativas. Sin embargo, las democracias deliberativas solo gozan de esa condición si aparte de estos espacios existen políticas y mecanismos que motiven los procesos deliberativos institucionales y no institucionales. Así, las instituciones basadas en un modelo que presupone el egoísmo de los miembros de la comunidad, protegiéndose frente a él contando con la apatía política como input cultural para funcionar y presuponiendo que amplísimos sectores de la sociedad no están capacitados para determinar sus propios horizontes y participar en las decisiones políticas, no generan incentivos para revertir todos estos fenómenos $y$, contrariamente, contribuyen a intensificarlos. Por esto, las sociedades democráticas deliberativas requieren de un diseño institucional que promueva el interés y la participación política, exigiendo con ello motivaciones imparciales y virtudes públicas a los ciudadanos. Sin embargo, la concreción de este objetivo requiere de una ciudadanía formada y capacitada para tomar decisiones, que favorezca el intercambio de opiniones y argumentos, y que se tome en serio los valores de autonomía pública, igualdad y dignidad de todos los seres humanos. De esta forma, se generan incentivos para que se alcance dicho objetivo y se activa un círculo virtuoso en el que los elementos culturales y las disposiciones motivacionales de los participantes enriquecen a los institucionales y viceversa.

Si bien existen sociedades como las latinoamericanas en donde el debate público ha tenido un deterioro sustancial como consecuencia de su modelo de gobierno, ello no significa que sea la única causa, pues como lo sostiene Nino (1997, pág. 224), la restricción a los medios masivos de información impide a las sociedades contar con los elementos fundamentales para realizar deliberaciones argumentadas y, por ende, democráticas. La restricción o manipulación de los medios de información para la ciudadanía conlleva un debate sesgado e ideológicamente carente de argumentos:

El deterioro del debate público en la sociedad no se debe simplemente a la dinámica del sistema presidencialista, sino que también responde a la forma en que operan los medios masivos de comunicación que controlan el proceso político. Estos transforman casi todos los hechos y debates en espectáculos superficiales preparados para entretener, dando lugar al fenómeno político que Giovanni Sartori ha descripto como "vídeo-poder". Estos espectáculos no intentan iluminar las controversias políticas y hacer reflexionar a la gente seriamente acerca de las posiciones ideológicas de los diferentes candidatos o acerca de las consecuencias de las políticas en disputa, sino que buscan sorprender a lo espectadores con el último escándalo, presentar a figuras patéticas como estrellas glamorosas y dirigir la atención hacia el ridículo o lo melodramático. Se puede obtener un beneficio de todo aquello que pueda ser sintetizado en una imagen o en un eslogan. Por supuesto, esto no favorece el debate moral pues como sostiene Robert Entman, los medios alimentan una espiral de demagogia, impactan negativamente sobre la racionalidad en el diseño de las políticas, elevan la tendencia hacia una reaseguración simbólica y evasión nostálgica de elecciones concretas y finalmente la falta de representación del público. (Nino, 1997, pág. 225). 
Por lo anterior, el acceso libre a la mayor cantidad de información imparcial contribuye no solo a generar espacios deliberativos democráticos caracterizados por su calidad argumentativa, sino que el acceso a la información relevante para el ciudadano a través de medios masivos es esencial para la calidad epistémica de la discusión pública, pues estos se vuelven los intermediarios en el ejercicio de la política por parte de la ciudadanía. En efecto, las TIC promueven la inclusión de la opinión ciudadana en los procesos de toma de decisiones, convirtiendo las posturas políticas más visibles a nivel horizontal entre sus pares y a nivel vertical en los estamentos de toma de decisiones

La consolidación de sociedades profundamente desiguales, heterogéneas y pluralistas; la globalización de la economía y la revalorización de la educación como instrumento para el cambio, han tenido un impacto directo en los procesos educativos, incluyendo los de educación cívica. Por esta razón, la implementación de las TIC debe generar una mayor interacción deliberativa que incentive una educación cívica pluralista e incluyente, que se caracterice por la deliberación y la calidad de los argumentos, basada en el respeto y claridad de estos en el desarrollo del proceso deliberativo. Por esta razón, las herramientas tecnológicas garantizan no solo una mayor participación política por parte de la ciudadanía, sino un trato más directo e igualitario entre los actores políticos, permitiendo que los procesos de participación ciudadana y de modernización del Estado confluyan a fortalecer la democracia a través del uso de las tıc para fortalecer la democracia, pues los ciudadanos al ser más conscientes de sus derechos y deberes pueden intervenir de manera más activa en las decisiones que los afectan:

Los nuevos avances tecnológicos han despertado esperanzas, todavía por concretar, en una mayor participación política por sus nuevos medios. O han suscitado, también, muy objetables medios de reforzamiento de la participación en las democracias representativas, como las DOP (deliberative opinion poli), para evitar que las decisiones políticas queden en manos de élites políticas sumamente cualificadas, sin mucha atención a masas electorales desmotivadas y sin preparación. Se trata de una muestra de electores seleccionados mediante sorteo que durante dos semanas se prepararían las más acuciantes preguntas del electorado y las formularían como si fueran la opinión supuestamente representativa del conjunto de la sociedad. Esta muestra de electores dirigiría sus preguntas a los candidatos no advertidos de estas inquietudes y trasmitiría, después, sus conclusiones e impresiones formadas al conjunto del electorado mediante emisión abierta en los medios de comunicación a la entera disposición de todos (Fishkin, 1992). Valga esta ingeniosa propuesta para mostrar la atención actual a los reflejos de la democracia directa sobre la democracia representativa. (Sauquillo, 2002, pág. 285).

La asunción de las tic en las democracias pluralistas permite lograr las potenciales funciones que estas encierran, al momento de fortalecer los contextos deliberativos, generando cambios sustanciales que resultan acordes con las nuevas demandas sociales, ${ }^{32}$ especialmente aque-

32 "Estos nuevos escenarios en los que se enmarca la educación ponen de manifiesto la necesidad de reorientar y llevar a cabo cambios 
Ilas que buscan satisfacer el conocimiento práctico en entornos de interacción social ${ }^{33}$ creados por los avances tecnológicos. Los métodos de educación cívica deben ser acordes con los nuevos usos que implica la introducción de la tecnología en la educación, ${ }^{34}$ pues este proceso es palpable e irreversible. ${ }^{35}$

sustanciales en el paradigma educativo, que permitan hacer frente a las nuevas demandas sociales" (Díaz, 2012, pág. 155)

33 "En la escuela, el docente organiza la actividad para la enseñanza y la lengua escrita. En cambio los eventos de lectura y escritura que surgen en la vida cotidiana se disponen con fines comunicativos y, por ello, son importantes contextos para la apropiación de los diversos usos de la lectura escrita. Es precisamente a través de la participación de este tipo de eventos donde el individuo aprende los usos no escolares de la lectura y la escritura. Como noción teórica, la participación se refiere al proceso de intervenir en actividades sociales, así como las relaciones que se establecen entre los diferentes actores" (Kalman, 2003, pág. 120).

34 Las TIC no eliminan los objetivos de los procesos de aprendizaje, por el contrario, los expande al crear nuevos soportes, formatos de almacenamiento y procesamiento de textos y funcionalidades, aportando novedosos modos de expresión, acceso a la información y vías para adquirir y compartir conocimiento (Lamarca, 2009). Así "la tecnología de los medios se pone al servicio de la didáctica, sus avances hacen prever un cambio en el trabajo docente. La preparación de software educativos, se ha convertido en uno de los escenarios de trabajo de los egresados de las facultades de educación; las salas multimediales resultan ser un laboratorio de primer orden para el trabajo del futuro docente." (De González, 2002, pág. 61).

"En la actualidad, frente a los requerimientos de investigación de los docentes, la escritura se hace más visible y, también más atemorizante para algunos. La investigación y esto es lo que atemoriza, solo comienza a ser nuevo conocimiento, conocimiento social, cuando se escribe y se publican los resultados." (Sánchez y Osorio, 2006, pág. 205). Es por ello que el docente de hoy debe ser consciente que los procesos educativos se están desarrollando a través del uso de las TIC, "herramienta didáctica acorde con los nuevos sujetos educativos provenientes de la cultura de la imagen." (De González, 2002, pág. $58)$.

35 Conviene destacar que la escuela difícilmente puede seguir el ritmo frenético con que se está operando está transformación. Aunque queden ya pocas personas y menos instituciones que todavía escriban a mano o con máquina mecánica o eléctrica, la escuela todavía sigue enseñando a escribir de modo analógico, con lápiz y sacapuntas, con todas las implicaciones que tiene: énfasis en cuestiones caligráficas y ortográficas, menos posibilidad de reformulación, etc. Indudablemente, este hecho debe resultar desmotivador para el aprendiz que -tenga o no ordenador en su casa- ve que en el centro escolar siguen enseñando a escribir de una manera que ya nadie usa en la comunidad (Cassany, 1999, p. 96). [Cursivas fuera del texto original]
El acceso y el uso estratégico de las TIC contribuye no solo a fortalecer los procesos deliberativos, sino que a su vez permite promover el desarrollo económico, la reducción de la pobreza y la democratización (libertad de expresión, derechos a la educación e información, control político-ciudadano y defensa de los derechos humanos). Por ello, el papel que estas podrían jugar resulta fundamental, siempre y cuando desempeñen un lugar central en la cooperación para el desarrollo de aquellas acciones orientadas al avance de la democracia. Si bien las TIC no son la panacea para los procesos democráticos, ${ }^{36}$ ello no impide que con su implementación, los procesos de enseñanza -especialmente los basados en EVA- ${ }^{37}$ sean más acordes con espacios

36 Sobre el particular menciona Barysch (2014): En sus inicios, los más entusiastas soñaban con que el mero acceso a internet ayudaría a difundir la democracia. No fue así. A fines de los años 90, un 4 por ciento de la población mundial usaba la red: hoy la cifra alcanza casi al 40 por ciento. Sin embargo, la proporción de países calificados como "no libres" o "parcialmente libres" por el observatorio de la democracia Freedom House apenas ha cambiado en ese periodo. En la batalla entre redes y jerarquías, la mayoría de las veces ganan estas últimas.

37 Por ende, el modelo de educación cívica basado en el uso de las TIC (EVA para la educación cívica) debe tener en cuenta los siguientes presupuestos:

“a) El aprendizaje debe tener lugar en entornos auténticos del mundo real. La experiencia social y con objetos es el catalizador primario del conocimiento, puesto que proporciona la actividad sobre la cual opera la mente.

b) El aprendizaje debe implicar negociación social y mediación. La interacción social proporciona el desarrollo de destrezas y conocimientos socialmente relevantes así como un mecanismo para las perturbaciones que pueden requerir adaptación individual.

c) Los contenidos y destrezas deben ser relevantes para el estudiante. El conocimiento sirve a una función adaptativa, por lo tanto, debe ser relevante con respecto a la situación actual del individuo (significados, metas y objetivos, etc.). Esta relevancia conduce a un aumento de la motivación en la medida en que el sujeto comprende la necesidad de cierto conocimiento.

d) Los contenidos y destrezas deben ser comprendidos dentro de la estructura de los conocimientos anteriores del aprendiz. Todo aprendizaje comienza con los conocimientos previos del individuo. Los errores son especialmente significativos para comprender las reglas y estructuras de los aprendices. Las nuevas experiencias de aprendizaje solo pueden asentarse en los conocimientos previos de los aprendices. 
de interacción donde se desarrollen presupuestos propios de una sociedad intercultural. ${ }^{38}$ Por lo anterior, podría afirmarse que a mayor acceso a la educación no solo hay más desarrollo de capital humano y económico, ${ }^{39}$ sino que permite la consolidación paulatina, pero sólida y eficaz, de los principios y valores democráticos.

e) Los estudiantes deben ser evaluados de manera formativa, de modo que esta información sirva para futuros aprendizajes. Las experiencias y actividades formativas deben basarse en los conocimientos previos, pero éstos no son directamente observables, son solo inferibles de la actuación de los aprendices. La evaluación formativa es la manera de obtener dicha información, necesaria para diseñar las siguientes experiencias y actividades de aprendizaje.

f) Los estudiantes deben ser estimulados a convertirse en aprendices autorregulados, automediados y autoconscientes. La metacognición es: a) conocimiento de la cognición (saber lo que uno sabe, saber lo que uno es capaz de hacer y saber qué hacer y cuándo) y b) regulación de la cognición (la tarea constante de planificar, monitorizar y evaluar el propio conocimiento y aprendizaje).

g) Los profesores sirven prioritariamente de guías y facilitadores del aprendizaje, no de instructores. El papel del profesor en el proceso de aprendizaje es crear experiencias para los estudiantes que les conducirán a la adquisición de conocimientos. Su papel es motivar, proporcionar ejemplos, discutir, facilitar apoyo y desafiar, pero no intentar actuar como un conductor del conocimiento.

h) Los profesores deben proporcionar múltiples perspectivas y representaciones de los contenidos. Experimentar múltiples perspectivas de un evento particular ofrece al estudiante los materiales necesarios para desarrollar múltiples representaciones de los hechos." Silva (2011, págs. 75 y 76 ). ya que permiten generar espacios adecuados para la interacción y el intercambio, favorecen la puesta en práctica de valores como la solidaridad y promueven nuevas estrategias de comunicación, de colaboración y de diálogo." (Díaz, 2012, pág. 163).

39 "Los niños de familias de bajos ingresos pueden beneficiarse del acceso a una enseñanza asistida por computadora que comprenda programas informáticos interactivos bien concebidos que propicien la adquisición de cualificaciones y de las competencias previstas en el plan de estudios. Un estudio a pequeña escala realizado en escuelas en zonas de bajos ingresos de Tel Aviv (Israel) mostró que los alumnos de quinto grado que utilizaban un programa de actividades didácticas interactivas asistidas por computadora, impartido mediante computadoras portátiles individuales, habían logrado mejoras en el aprendizaje mucho más importantes que los alumnos que recibían la enseñanza en un entorno tradicional. El programa informático especialmente diseñado, ajustado al plan de estudios nacional, permitió a los docentes proporcionar distintos materiales a los alumnos con diferentes niveles de rendimiento y dejarlos trabajar según sus propias capacidades (Rosen y Manny-lkan, 2011)." (Unesco, 2014, pág. 501).
Ahora, ¿qué mecanismos políticos y jurídicos deben ser creados para una efectiva educación cívica para sociedades democráticas deliberativas? Siguiendo a Fernández (1995, pág. 80) estos podrían resumirse en tres puntos:

1. El reconocimiento jurídico de un marco de autonomía moral y de libertad personal, solamente limitado por la exigencia de compatibilidad con la autonomía y la libertad de los demás. ${ }^{40}$

2. El respeto y garantía de los derechos fundamentales, ${ }^{41}$ pues estos no solo fundamentan axiológicamente la democracia, sino que sirven como límite a su actuación, es decir, representan un coto vedado a las decisiones democráticas que los nieguen. Ello quiere decir que los derechos humanos se encuentran en una situación de mayor jerarquía que el propio sistema democrático. "Por tanto, cualquier decisión democrática que atente a los derechos de las minorías se convierte en un atentado a los derechos humanos y, por consiguiente, en una decisión injusta" (Fernández, 1995, pág. 80).

40 "El respeto de las minorías no es más que una consecuencia del reconocimiento del derecho a la autonomía y a la libertad personales, en cuanto a la elaboración de los planes de vida y de los modos personales de acceder a lo que se considera lo bueno o lo que puede posibilitar la felicidad." (Fernández García, 1995, pág. 78).

41 "Hoy los derechos humanos fundamentales representan un código ético, político y jurídico con vocación de universalidad. Se trata de la realización y positivación (en el sentido jurídico) de una serie de valores fundamentales en la idea de dignidad humana y realizadores de ella, como la autonomía, la seguridad, la libertad o la igualdad, valores que se encuentran tan cerca de la historia de Europa. No hay democracia sin respeto y garantía de los derechos humanos, y no puede existir respeto y garantía de los derechos humanos al margen de la democracia. La historia y la actualidad son ejemplos de ello." (Fernández García, 1995, pág. 80). 
3. La institucionalización de la tolerancia, pues esta se encuentra vinculada a la existencia del fenómeno del pluralismo y es la actitud más acorde con la aceptación de ese fenómeno social. ${ }^{42}$

Finalmente, la incorporación de las tic en la educación cívica no garantiza por sí sola la inclusión, la equidad social y la eficacia de los derechos fundamentales y los valores democráticos. ${ }^{43}$ Sin embargo, el desafío de una sociedad democrática e intercultural será poder comunicar estos criterios a través de la implementación de las tıc. ${ }^{44}$ Así, el uso de estas debe

42 "Con la propuesta de la institucionalización de la tolerancia me refiero a ésta no sólo como actitud o virtud cívica privada, sino también como virtud cívica de carácter público, es decir, como virtud estimulada y apoyada por las instituciones políticas y jurídicas." (Fernández García, 1995, pág. 82).

43 "Sólo sabemos que las decisiones públicas tienen efectos no queridos, incluso efectos contrarios a los queridos, efectos perversos a los que somos totalmente ajenos. Pero ignoramos si esos efectos llevan hacia adelante o hacia atrás, si van a producir un orden "superior" o un total desorden." (Laporta, 2000, pág. 133).

44 Sobre este aspecto Vargas Llosa (2014) considera que contrario a lo que piensa la mayoría, las TIC generan discriminación porque son producto de las élites para las élites: "Hay quienes creen que la gran revolución audiovisual de nuestro tiempo está creando por primera vez una cultura democrática. Yo creo que eso no es verdad, que lo que ha creado este fenómeno es una información que llega a todo el mundo por primera vez o llega a un número que antes era inconcebible. Eso sí es verdad. Ha transformado enteramente nuestra época y eso no está en discusión. Lo acepto y creo que hay muchos elementos positivos como que cada vez va a ser más difícil establecer sistemas de censura, la tecnología dinamita los sistemas de censura y eso es muy positivo. Ahora, confundir la cultura con la información es equivocado. La cultura siempre fue y siempre será elitista.

No todo el mundo va a gozar con el Ulises de Joyce o con una ópera de Wagner. Esas jerarquías o diferenciación de especialidades está desapareciendo hoy con la idea de que todo es cultura y nada es cultura. Eso ha creado una enorme confusión que está desnaturalizando la función de la cultura que era crear ciudadanos críticos, insatisfechos, que no se dejaban manipular. Hay una pasividad, un conformismo que se deriva de esa enorme idealización de la tecnología como seudoproducto cultural y creo que eso tiene graves peligros para la sociedad, la libertad y la democracia. Ese es el sentido de ese ensayo y me alegro que haya debate porque es un tema que hay que discutir, porque si la cultura se convierte en entretenimiento y empieza a competir con las series televisivas, con el circo, creo que por primera vez puede llegar a materializarse formar y enseñar otros valores que permitan a las futuras generaciones desenvolverse dentro de la cultura digital de una forma democrática, responsable y solidaria. Por esta razón, es necesario continuar en la creación -o reinvención-e implementación de espacios deliberativos que permitan explorar y explotar las potencialidades que estas herramientas tecnológicas ofrecen para lograr cambios sustanciales en las democracias actuales, pues como lo sostiene Waluchow: “la democracia significa que el pueblo mismo es en alguna medida, el responsable de la determinación de las leyes por las que es gobernado." (2009, pág. 64).

\section{Referencias}

1. Aguado Odina, M. (s. f.). La educación intercultural: concepto, paradigmas, realizaciones. Recuperado de: http://red.pucp. edu.pe/ridei/wp-content/uploads/biblioteca/090804.pdf

2. Barysch, B. (2014). La falsa promesa de la democracia digital. Recuperado de: http://www.eltiempo.com/tecnologia/internet/ARTICULO-WEB-NEW_NOTA_INTERIOR-13719955.html. Fecha de consulta: 30 de marzo de 2015.

3. Beltrán Pedreira, E. (2002). Diversidad y deberes cívicos. En E. Díaz y J. Colomer. Estado, justicia, derecho. Madrid: Alianza editorial.

\footnotetext{
la pesadilla de Orwell de un mundo de grandes especialistas, gente muy bien informada pero completamente autómata, manipulada por los poderes que controlan la tecnología y que pueden llegar, a través de una supuesta revolución científica, a la dictadura."
} 
4. Capacho, J. (2011). Evaluación del aprendizaje en espacios virtuales - TIC. Barranquilla: Universidad del Norte.

5. Carbonell Sebarroja, J. (2005). El profesorado y la innovación educativa. En P. Cañal de León, La innovación educativa. Madrid: Universidad Internacional de Andalucía.

6. Cassany, D. (1999). Construir la escritura. Barcelona: Editorial Paidós.

7. Colombo Villarasa, C. (2007). e-Participación: Las tic al servicio de la innovación democrática. Barcelona: Editorial UOC.

8. Corte Constitucional. Sentencia T-406 de cinco (5) de junio de 1992 (M. P.: Ciro Angarita Barón).

9. Corte Constitucional. Sentencia T-337 de diecisiete (17) de julio 1997 (M. P.: Carlos Gaviria Díaz).

10. Corte Constitucional. Sentencia T-179 de 24 de febrero de 2000 (M. P.: Alejandro Martínez Caballero).

11. Corte Constitucional. Sentencia C-778 veintisiete (27) de julio de 2005 (M. P.: Manuel José Cepeda).

12. Corte Constitucional. Sentencia C-208 de veintiuno (21) de marzo de 2007 (M. P.: Rodrigo Escobar Gil.

13. David A., P. y Foray, D. (s. f.). Una introducción a la economía y a la sociedad del saber.
Recuperado de: http://www.oei.es/salactsi/ david.pdf

14. De Antonio Gómez, A. (2001). Pedagogía constitucional: un análisis jurídico-político de la Constitución de 1991. Bogotá D. C.: Universidad Jorge Tadeo Lozano.

15. De González, B. (2002). El hipertexto como herramienta didáctica. En El oficio de investigar - Educación y pedagogía frente a nuevos retos. Colección: Desarrollos en Investigación en Educación n. ${ }^{\circ}$ 3. Bogotá D. C.: Universidad Pedagógica Nacional.

16. De Zubiría Samper, J. (2006). Los modelos pedagógicos: hacia una pedagogía dialogante. Bogotá D. C.: Editorial Magisterio.

17. Díaz, T. (2012). La función de las tic en la transformación de la sociedad y de la educación. En R. Carneiro, J. Toscano y T. Díaz. Los desafíos de las tic para el cambio educativo. Madrid: Organización de Estados Iberoamericanos (oei) y Fundación Santillana.

18. Fernández García, E. (1995). Filosofía, política y derecho. Madrid: Marcial Pons.

19. Ferrajoli, L. (1995). Derecho y razón - teoría del garantismo penal. Madrid: Trotta.

20. Ferrajoli, L. (2011). Principia iuris. Teoría del derecho y de la democracia, (t. 2), Teoría de la democracia. Madrid: Trotta.

21. Fuster, M. (2012). Concepción de la participación en entornos en línea: lecciones y 
retos para las experiencias de democracia digital. En I. Ramos Vielba y E. Campos Domínguez, Ciudadanía en 3D: Democracia Digital Deliberativa. Un análisis exploratorio. Barcelona: Edhasa.

22. Häberle, P. (2003). El estado constitucional. Lima: Fondo Editorial Universidad Nacional Autónoma de México (unam), Pontificia Universidad Católica del Perú (pucp).

23. Habermas, J. (1987). Teoría de la acción comunicativa. Racionalidad de la acción y racionalización social. V I. Madrid: Taurus.

24. Kalman, J. (2003). El acceso a la cultura escrita: la participación social y la apropiación de conocimientos en eventos cotidianos de lectura y escritura. Revista Mexicana de Investigación Educativa, 17 (VIII).

25. Laporta, F. (2000). Entre el derecho y la moral. México D. F.: Editorial Fontamara.

26. Leiva Ramírez, E. y Muñoz González, A. L. (2014). Las tecnologías de la información y la comunicación (tic) en los modelos pedagógicos dialogantes para la pedagogía constitucional. Revista de Derecho Público, 32.

27. Martí, J. (2006). La república deliberativa: una teoría de la democracia. Madrid: Marcial Pons.

28. Mochi, P. (2001). Nuevas tecnologías y democracia participativa: propuestas para desarrollar líneas de investigación. Recupera- do de: http://www.citidep.pt/papers/pma/ prud_gto01.html

29. Nino, C. (1997). La constitución de la democracia deliberativa. Barcelona: Editorial Gedisa.

30. Organización de las Naciones Unidas para la Educación la Ciencia y la Cultura [Unesco]. (2014). Enseñanza y aprendizaje: lograr la calidad para todos - Informe de Seguimiento de la ept en el mundo. París: Unesco.

31. Ortíz Ocaña, A. (2009). Pedagogía y docencia universitaria. Hacia una didáctica de la educación superior. (t. 1). Ediciones cepedid.

32. Ortíz, O. (2004). Lectura y escritura en la era digital. Desafíos que la introducción de las tic impone a la tarea de estimular el desarrollo del lenguaje en niños jóvenes. Recuperado de: http://www.uib.es/depart/gte/ edutec-e/revelec17/ortiz_16a.htm

33. Prieto Sanchís, L. (2002). Derechos fundamentales, mentales, neoconstitucionalismo y ponderación judicial. Lima: Palestra.

34. Said Hung, E. (2009). TIC y periodismo digital en el contexto escolar. En H. Said et al., La educación como espacio de desarrollo para Barranquilla. Barranquilla: Alcaldía de Barranquilla-Universidad del Norte.

35. Sánchez, J. y Osorio, J. (2006). Lectura y escritura en la educación superior: diagnósti- 
co, propuestas e investigaciones. Medellín: Universidad de Medellín.

36. Sartori, G. (2001). La sociedad multiétnica - pluralismo, multiculturalismo y extranjeros. Madrid: Taurus.

37. Sartori, G. (2009). La democracia en 30 lecciones. Madrid: Taurus.

38. Sauquillo, J. (2002). Obligación política, ciudadanos y otros sujetos de derecho. En E. Díaz y J. L. Colomer, Estado, justicia, derecho. Madrid: Alianza Editorial.

39. Schmelkes, S. (s. f.). La interculturalidad en la educación básica. Recuperado de: http:// www.amdh.com.mx/ocpi/documentos/ docs/6/16.pdf
40. Silva Quiroz, J. (2011). Diseño y moderación de entornos virtuales de aprendizaje (eva). Barcelona: Editorial uoc.

41. Trujillo García, S. (2008). La sujetualidad: un argumento para implicar propuesta para una pedagogía de los afectos. Bogotá D. C.: Pontificia Universidad Javeriana.

42. Vargas Llosa, M. (2014). La cultura siempre fue y siempre será elitista. Recuperado de: http://www.elespectador.com/noticias/nacional/guerrilla-debe-firmar-una-rendicionsu-desaparicion-articulo-486610 . Fecha de consulta: 13 de abril de 2015.

43. Waluchow, W. J. (2009). Una teoría del control judicial de constitucionalidad basada en el common law: un árbol vivo. Madrid: Marcial Pons. 